\title{
Valopicitabine Dihydrochloride
}

National Cancer Institute

\section{Source}

National Cancer Institute. Valopicitabine Dihydrochloride. NCI Thesaurus. Code C72874.

The dihydrochloride salt of valopicitabine, a 3-O-valine ester prodrug form of the nucleoside analog 2'-C-methylcytidine with anti-hepatitis C virus (HCV) activity. Upon administration, valopicitabine is converted into 2'-C-methylcytidine; upon phosphorylation into its 5-triphosphate form, this metabolite inhibits viral RNA chain elong ation and viral RNA-dependent RNA polymerase activity. This blocks viral production of HCV RNA and thus viral replication. 